\title{
BAMBUSA TULDOIDES: ANÁLISE DE VIABILIDADE DA PRODUÇÃO DE COMPÓSITOS DE FIBRAS DE BAMBU E ACETATO DE POLIVINILA
}

\author{
BAMBUSA TULDOIDES: FEASIBILITY ANALYSIS OF THE PRODUCTION OF BAMBOO \\ FIBER AND PLYVINYL ACETATE COMPOSITES
}

Alessandra de Castro Silva Pedrangelo1; Diegle Barbosa Rufato2; Sergio Trajano Franco Moreiras ${ }^{3}$;

1. Pós-graduada, Mestre, Programa de Pós-Graduação em Sustentabilidade, Universidade Estadual de Maringá - UEM. alepedrangelo@gmail.com

2. Graduado no Curso de Engenharia Civil, Campus Umuarama/PR, Universidade Estadual de Maringá - UEM. ra67593@uem.br

3. Orientador, Doutor, Departamento de Tecnologia, UEM. Professor da Universidade Estadual de Maringá (UEM).strajano@gmail.com

\section{RESUMO}

Embora o aumento da população mundial tenha gerado um avanço substancial no consumo da madeira o fornecimento deste material tanto das florestas naturais quanto de reflorestamentos tem diminuído. Conforme Mera (2014) a alternativa para a substituição da madeira é o bambu pois é o material mais notável para diminuição da pressão sobre os recursos naturais florestais. Esta pesquisa apresentou a avaliação da potencialidade para confecção de painéis compósitos de partículas de bambu da espécie Bambusa tuldoides com PVAc. Foram avaliadas as propriedades físicas e mecânicas do compósito segundo as normas ABNT NBR 14810-2 (2013), NBR 7190 (1997), ANSI A208 (1999), EN 310 (1993), WPIF 2G (2018) para a determinação da densidade, inchamento em espessura, absorção d'água, Módulo de Elasticidade e Módulo de Ruptura em ensaios de compressão e flexão. Apesar da diversidade, os resultados da presente pesquisa foram satisfatórios e, portanto, indicam potencialidade tecnológica para a produção de painéis compósitos.

\section{Palavras Chave}

Painéis de Partículas de Média Densidade; Materiais com Alta Ductilidade; Bambusa Tuldoides.

\begin{abstract}
Although the increase in the world population has generated a substantial advance in wood consumption, the supply of this material from both natural forests and reforestation has decreased. According to Mera (2014) the alternative for replacing wood is bamboo because it is the most remarkable material for reducing the pressure on natural forest resources. This research presented the evaluation of the potentiality for the manufacture of composite panels of bamboo particles of the species Bambusa tuldoides with PVAc.
\end{abstract}


The physical and mechanical properties of the composite were evaluated according to abnt nbr 14810-2 (2013), NBR 7190 (1997), ANSI A208 (1999), EN 310 (1993), WPIF 2 G (2018) for density determination, swelling in thickness, water absorption, Modulus of Elasticity and Rupture Modulus in compression and bending tests. Despite the diversity, the results of the present study were satisfactory and, therefore, indicate technological potential for the production of composite panels.

\section{KEY WORDS}

Medium Particle Panels; High Ductility Materials; Bambusa Tuldoides.

\section{INTRODUÇÃO}

Atualmente os materiais compósitos a base de madeira, são empregados principalmente na forma de painéis para a construção civil. A produção de painéis industrializados no Brasil no período de 2010 a 2019 foi em média de 7.579 mil m³ , representando um crescimento de 33,83\% quando comparado com a década anterior. Os responsáveis por aproximadamente $90 \%$ do crescimento desse setor foram atribuídos as exportações, dados obtidos pela Indústria Brasileira de Árvores- IBÁ (2019). Portanto há um grande mercado de consumo de painéis industrializados no mundo.

Segundo Associação Brasileira de Produtores de Florestas Plantadas - ABRAF (2012), as principais espécies para obtenção de matéria prima para composição de painéis são o Pinus sp. e Eucalyptus sp. Essas espécies de reflorestamento atingem a idade de corte entre 7 a 10 anos, porém a demanda por este material está em crescente expansão, necessitando cada ano de maiores campos de cultivo podendo diminuir gradativamente áreas de outras culturas.

Com isso aumenta-se a busca por soluções inovadoras que possam ser utilizadas como matéria prima alternativa da madeira para a utilização na formação de compósitos. Um dos materiais que tem sido mais pesquisado fora do Brasil é o bambu que entre outras vantagens tem rápido crescimento e idade de corte de 3 anos, sendo, portanto, sua produtividade maior que das espécies convencionalmente utilizadas (MERA, 2014).

Dentre as vantagens do cultivo podem-se destacar algumas como o intenso sequestro e retenção de $\mathrm{CO}_{2}$, o possível cultivo em terrenos acidentados para o combate da erosão, acelerado crescimento e rápida maturação podendo a touceira se manter produtiva e sem replantio por aproximadamente 30 anos, sendo estes os principais aspectos ambientais 
positivos para a cultura do bambu segundo Pereira (2016). A grande diversidade de produtos que podem ser obtidos por meio da industrialização das fibras, são fatores que revelam a potencialidade do uso do bambu em diversos setores (VIEIRA et al., 2016).

Uma das espécies que possui melhor adaptação em território nacional é a Bambusa tuldoides, gramínea originária da Ásia, pertence ao grupo dos entouceirantes, ou seja, que formam grandes moitas. Os colmos ou hastes têm altura média de $12 \mathrm{~m}$, o crescimento longitudinal é de 1,2 m/ano, o diâmetro médio dos colmos na base é de $6 \mathrm{~cm}$ e a temperatura mínima que a espécie suporta é de $9^{\circ} \mathrm{C}$. A coloração da haste vai de verde escuro brilhante à amarelo dependendo da idade, é incomum acontecer floração nessa espécie a absorção da água e nutrientes é feita pelas raízes ligadas aos rizomas. Pela grande flexibilidade dos colmos esta espécie é vastamente utilizada na confecção de andaimes, quebra ventos e cercas (JAYARAMAN, 2019).

Para fabricação de painéis a resina mais difundida para a aglutinação das partículas é a ureia-formaldeído. Esse adesivo é utilizado tradicionalmente pelas indústrias moveleiras, por ter baixo custo, boa resistência ao calor e menor tempo de reação à prensagem a quente quando comparada com outras resinas de acordo com Maloney (1996), porém com a desvantagem de ser um agente cancerígeno. Segundo Melo (2010), os adesivos à base de tanino vegetal e a resina poliuretana (PU) de óleo de mamona (SANCHÉZ, 2017), são materiais renováveis que vem progressivamente sendo utilizados industrialmente na produção de painéis.

Com o objetivo de prosseguir com as pesquisas por adesivos menos prejudiciais à saúde e ao meio ambiente, a presente pesquisa buscou inserir neste contexto a utilização do acetato de polivinila (PVAc), comercialmente conhecido como cola branca, para a confecção de painéis de partículas de bambu. A cola branca é atóxica, não possui odor e sua secagem é feita a frio. Sua desvantagem é sua grande solubilidade em água. Para atingir esta meta foram confeccionados corpos de prova do compósito e aplicados diferentes ensaios cujos resultados auxiliassem na busca de dados que indicassem a viabilidade do produto final para uso na arquitetura e construção civil.

\section{MATERIAIS E MÉTODO}

\subsection{MANEJO}


A espécie Bambusa tuldoides é uma gramínea de propagação assexuada por processos vegetativos por meio de estacas de rizomas, ramos e colmos (BERALDO, 2003). De maneira geral, o cultivo desta espécie no Brasil é realizado para suas moitas forneçam barreiras acústicas ou maciços ornamentais em espaços abertos.

Os colmos foram coletados na zona rural localizada na região metropolitana do município de Umuarama noroeste do Estado do Paraná (230 45’59.0" S 530 18'07.2" W). Os colmos coletados tinham em média 20 metros de comprimento e após o corte permaneceram em posição vertical para escoamento natural da seiva e água armazenada em sua estrutura.

O processamento dos colmos foi realizado de acordo com as etapas detalhadas em seguida. Após 30 dias os colmos foram divididos em frações de 1,50 $\mathrm{m}$ e o material foi transportado para o setor de podas de árvores da Prefeitura Municipal de Umuarama, onde passaram por máquina de trituração de galhos.

\subsection{PRODUÇÃO DE FIBRAS}

Após a trituração, percebeu-se que o material ainda apresentava um teor de umidade bastante elevado, então se iniciou um processo de secagem ao ar por 5 dias, com o material disposto em lonas plásticas no pátio da Universidade Estadual de Maringá, sendo revolvido diariamente durante 6 a 8 horas. Os cavacos de bambu depois da perda da umidade superficial foram acondicionados em duas lonas no laboratório de materiais, para posterior seleção granulométrica.

Para a triagem dos cavacos, foi utilizada uma peneira comum de obra e selecionados os particulados graúdos, médios e serragem, sendo os particulados médios reservados para a próxima etapa.

Verificou-se que os particulados médios não haviam atingido a dimensão ideal sugerida na literatura (MORAIS, 2018), portanto o material foi submetido a outra seleção granulométrica em peneiras de malha quadrada, com a exclusão do pó e reserva das partículas retidas na peneira de malha $1,18 \mathrm{~mm}$. O material retido foi submetido à polpação similar a sugerida por Azzini (1998) onde os particulados foram submetidos à trituração mecânica realizada em liquidificador comum com tempo de desfibramento de 60 segundos e uma proporção de particulados e água destilada de 1:33. Esse procedimento contempla dupla função, retirada necessária de amido por ser elemento atrativo para insetos e fungos, 
e quebra da lignina por proporcionar excesso de rigidez às paredes celulares. O material pós-polpação, passou por período de secagem natural.

\subsection{PREPARAÇÃO DOS CORPOS DE PROVA}

Anterior à modelagem dos corpos de prova, foram efetuadas experimentações de proporção de traços das partículas e adesivo PVAc (Acetato de Polivinila). Dentre os vários traços testados optou-se pela proporção de $1: 4$, ou seja, $20 \%$ da massa total em massa seca coube aos particulados e $80 \%$ ao adesivo. A modelagem inicial dos corpos de prova foi fase necessária para que fosse possível avaliar a granulometria das partículas, a interação partícula/matriz, os possíveis traços dos materiais, o tempo de cura dos corpos de prova, a desmoldagem e os ensaios pós-cura. Os corpos de prova tem suas dimensões adequadas aos ensaios através de cortes e lixamento.

\subsection{ENSAIOS FÍSICOS}

\subsubsection{Ensaio de densidade}

A densidade foi determinada por meio de ensaios com 6 seis corpos de prova com dimensão de $20 \times 20 \times 40$ mm O cálculo da densidade seguiu de acordo com a norma ABNT NBR 14810-2, 2018 sendo determinada pela expressão (equação 1):

$$
\rho=\frac{m s}{V_{\text {sat }}} \times 10^{3}
$$

Onde $\rho$ é a densidade, em $\mathrm{kg} / \mathrm{m}^{3} ;$ ms é a massa seca, em gramas (g); Vsat é o volume saturado, em centímetros cúbicos $\left(\mathrm{cm}^{3}\right)$.

$\mathrm{O}$ corpo de prova foi submetido à secagem em estufa a $103^{\circ} \mathrm{C} \pm 2^{\circ} \mathrm{C}$ e suas medida efetuadas a cada $6 \mathrm{~h}$ até que a variação fosse menor ou igual a $0,5 \%$, para depois ser determinada a massa seca (ms) em balança digital.

O volume saturado (Vsat) foi determinado pelas dimensões finais do corpo-de-prova submerso em água até que fossem atingidas dimensões constantes ou com no máximo uma variação de $0,5 \%$ em relação à medida anterior, como recomendado pela norma $A B N T$ NBR 7190.

\subsubsection{Ensaio de inchamento em espessura}


Para realização do ensaio de inchamento em espessura $2 \mathrm{~h}$ e 24h, foram utilizados 6 corpos de prova para cada tratamento com dimensão de $20 \times 20 \times 40 \mathrm{~mm}$. $O$ ensaio foi adaptado das especificações da NBR 14810-2 (2013). Após terem sido lixados e identificados, foram anotados os dados referentes à medição da espessura no centro de cada corpo de prova com paquímetro com uma resolução de $0,01 \mathrm{~mm}$, e anotados os dados de suas massas em balança semi-analítica.

Posteriormente, os corpos de prova foram dispostos em dois recipientes com água destilada, de maneira que se mantivessem submersos à $25 \mathrm{~mm}$ abaixo da superfície da água. Após $2 \mathrm{~h}$ e $24 \mathrm{~h}$ de imersão, os corpos de prova foram retirados da água e colocados sobre superfície absorvente para liberar o excesso. Em seguida, mediram-se as espessuras dos corpos de prova em seus respectivos centros. Verificou-se a porcentagem do aumento de espessura de cada corpo de prova para posteriormente serem comparadas com o valor do parâmetro indicado na norma.

\subsubsection{Ensaio de absorção d'água}

Com o objetivo de manter a integridade do adesivo, os corpos de prova passaram por 5 tratamentos. Os impermeabilizantes utilizados foram: goma laca, verniz acrílico, multiseladora, óleo de linhaça e cera de carnaúba. Após o tempo de secagem recomendada pelo fabricante, foram submetidos a teste de absorção de água para verificação da eficiência destes tratamentos. Os corpos de prova foram observados durante 48h, após este período foram retirados da água e depositados em papel absorvente para retirada do excesso, e passaram por verificação da massa em balança de precisão.

\subsection{ENSAIOS MECÂNICOS}

O comportamento prévio dos materiais submetidos a cargas em ensaios mecânicos, é fundamental para antecipar o desempenho destes em situações reais.

\subsubsection{Ensaio de compressão}

O ensaio de compressão foi realizado com objetivo de determinar o módulo de elasticidade e de ruptura dos corpos de prova. Foram confeccionados 12 corpos de prova

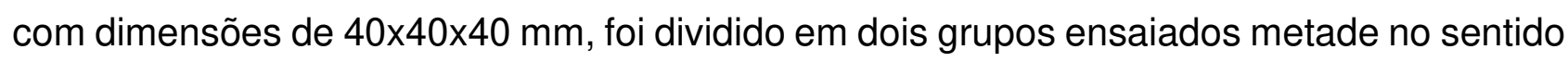
paralelo ao sentido preferencial da fibra e os outros no sentido normal as fibras. Foram 
medidas as dimensões da seção transversal dos corpos de prova e colocados um a um na máquina universal de ensaios eletromecânica, marca EMIC Laboratório de materiais da UEM.

Foi adotada a velocidade de $5 \mathrm{~mm} / \mathrm{min}$ e um carregamento de $10 \mathrm{MPa} / \mathrm{min}$, até que ocorresse a ruptura (NBR 7190). Foram então registradas as cargas máximas atingidas para romper os corpos de prova, expressas em newtons.

O objetivo deste ensaio foi a determinação da curva tensão x deformação. A partir dos resultados determina-se a tensão de ruptura, o módulo de elasticidade na compressão (E) sendo que este é determinado no trecho elástico. A tensão de compressão foi determinada pela expressão (equação 2):

$$
\sigma c=\frac{F}{A}
$$

Em que $\sigma c$ é a resistência a compressão, em $\mathrm{N} / \mathrm{mm}^{2}(\mathrm{MPa})$; F é a máxima força de compressão aplicada durante o ensaio, em newtons; A é a área inicial da seção transversal comprimida, em milímetros quadrados.

\subsubsection{Determinação do módulo de elasticidade}

O Módulo de Elasticidade (MOE) foi determinado pela expressão (equação 3):

$$
E=\frac{\Delta \sigma}{\Delta \varepsilon}
$$

Onde $E$ é o módulo de elasticidade; $\Delta \sigma$ são as tensões de compressão no trecho elástico; $\Delta \varepsilon$ são as deformações no trecho elástico.

A deformação é determinada pela seguinte expressão (equação 4):

$$
\varepsilon=\frac{\delta}{h}
$$

Onde $\varepsilon$ é a deformação, em $\mathrm{mm} ; \delta$ é o encurtamento, em $\mathrm{mm} ; h$ é a altura do corpo de prova, em $\mathrm{mm}$.

\subsubsection{Ensaio de flexão}

Flexão segundo a norma ABNT NBR 7190 (1997) e NBR 14810-2 (2006), é definida como a resistência que um corpo de prova apoiado em seus extremos e submetido a uma força aplicada ao seu centro até a ruptura. O módulo de ruptura (MOR) consiste na medição 
da capacidade máxima que um material suporta uma carga central aplicada lentamente por um curto espaço de tempo. Para os ensaios de tração na flexão foram confeccionados 6 corpos de prova adotando-se o comprimento do vão de $100 \mathrm{~mm}$. As dimensões do corpo de prova confeccionados foram de $120 \times 40 \times 20 \mathrm{~mm}$. O carregamento foi de $7 \mathrm{MPa} / \mathrm{min}$ e o resultado expresso em megapascals.

\subsubsection{Resistência à tração na flexão}

O objetivo deste ensaio é a determinação da curva de resistência na flexão $x$ deformação. A partir dos resultados foram determinados o módulo de ruptura (MOR), o módulo de elasticidade na flexão (E). A resistência na flexão é determinada pela expressão (equação 5):

$$
\sigma t f=\frac{3 F l}{2 b h^{2}}
$$

Onde $\sigma \mathrm{tf}$ é a resistência à tração na flexão, em megapascals; $\mathrm{F}$ é a força de flexão aplicada durante o ensaio, em newtons; I é o vão do ensaio, $100 \mathrm{~mm}$ (adotado); b é a base do corpo de prova, em mm; h é a altura do corpo de prova, em $\mathrm{mm}$.

\subsubsection{Determinação do módulo de elasticidade}

De acordo com a ABNT NBR 7190 (1997), o módulo de elasticidade é determinado pela expressão (expressão 6):

$$
E=\frac{\Delta \sigma}{\Delta \varepsilon}
$$

Onde $E$ é o módulo de elasticidade; $\Delta \sigma$ é a tração na flexão no trecho elástico; $\Delta \varepsilon$ são as deformações no trecho elástico.

O resultado do ensaio é a média dos resultados dos corpos de prova ensaiados, expresso em newtons por milímetros quadrado, com precisão de $1 \mathrm{~N} / \mathrm{mm}^{2}$ para o MOR e de $10 \mathrm{~N} / \mathrm{mm}^{2}$ para MOE.

A deformação dos corpos de prova é determinada pela expressão (equação 7):

$$
\varepsilon=\frac{6 \delta v h}{L^{2}}
$$

Onde $\varepsilon$ é a deformação; $\delta v$ é o deslocamento vertical, em $\mathrm{mm} ; h$ é a altura do corpo de prova, em $\mathrm{mm}$; L é o comprimento do corpo de prova, em $\mathrm{mm}$. 


\subsection{ANÁLISES QUÍMICAS}

Para avaliar o tratamento mecânico, compósito, interação com a cola branca e as possíveis diferenças químicas entre as duas espécies, foram efetuadas quatro técnicas de análises. Para a análise das microestruturas foram utilizadas duas técnicas de espectroscopia de infravermelho (FTIR) e Raman. Estas são técnicas complementares utilizadas para identificação dos grupos funcionais existentes nas fibras e suas ligações químicas existentes em uma molécula de materiais em estado sólido, líquido ou gasoso. Embora sejam técnicas que forneçam informações muito semelhantes se baseiam em maneiras diferentes de obtenção de resultados. Para o FTIR os resultados são obtidos a partir da absorção de radiação e para o Raman por meio do espalhamento da energia irradiada (BARBOSA, 1979; FREDERICCI, 2016; RODRIGUES, 2012).

Para análise das modificações das fibras como deformações, rupturas, danos da microestrutura e aspectos estruturais das partículas e do compósito utilizou-se a técnica de Microscopia Eletrônica de Varredura (MEV). O equipamento utilizado foi modelo Quanta 250 (FEI Company). Acoplado ao MEV e utilizando o mesmo grupo de amostras, foi utilizada a análise por EDS.

\subsubsection{Espectroscopia de infravermelho (FTIR)}

O princípio desta espectroscopia tem por base a reflexão de feixes de radiação, ou seja, detecção da quantidade de radiação que passa de um meio mais denso (cristal de ATR) para um meio menos denso (amostra). Essa técnica possibilita a identificação das ligações químicas para posterior classificação dos grupos funcionais presentes na superfície de materiais orgânicos e inorgânicos.

O equipamento utilizado para realizar as análises de espectroscopia foi FTIR-ATR do modelo Vertex 70v da marca Bruker. Para caracterização as amostras foram divididas em duas partes: a primeira misturada ao adesivo e a segunda in natura e então submetidas a varredura na faixa de 4000 a $400 \mathrm{~cm}^{-1}$.

\subsubsection{Espectroscopia Raman}

A espectroscopia Raman é uma técnica utilizada para a determinação da composição de um material fornecendo informações sobre as vibrações moleculares permitindo a 
caracterização da sua estrutura molecular. $O$ equipamento utilizado foi o espectrômetro Vertex70v da marca Bruker. A análise em espectroscopia Raman, foi importante na identificação de elementos químicos, fornecendo dados complementares a técnica de FTIR.

\subsubsection{Microscopia Eletrônica de Varredura (MEV)}

Para esta análise, a amostra foi feita do pó da fibra de bambu dividida em duas partes in natura e misturada à "cola branca". Em seguida, foram fixadas com fita dupla face de carbono em pequenas placas de metal ("stubs") e para que houvesse melhor condutividade de elétrons foi usada uma camada de ouro em metalizador da marca BALZERS (SCD 050). Foram analisadas e avaliadas a microestrutura das partículas de bambu e superfícies fraturadas.

\subsubsection{Análise química em EDS}

A análise por EDS (Energy Dispersive $X$-ray Spectroscopy) é uma ferramenta muito útil para a identificação de dados relacionados com a química inorgânica de materiais. É um equipamento acoplado ao MEV que busca um mapeamento elementar nas mesmas amostras usadas na análise anterior. É um procedimento considerado não destrutivo que permite $o$ acesso a imagens gráficas não quantitativas.

A análise química por EDS (Energy Dispersive X-Ray Spectroscopy) permitiu a identificação de elementos químicos inorgânicos sem, no entanto, apresentar uma quantificação dos mesmos.

\section{RESULTADOS E DISCUSSÃO}

\subsection{PROPRIEDADES FÍSICAS}

\subsubsection{Ensaio de inchamento em espessura}

Os ensaios de inchamento são práticas comuns para o controle de qualidade em indústrias de chapas e painéis, pois seus resultados são indicativos da coesão entre partículas e adesão com a matriz (resina ou adesivo). O resultado é a média dos inchamentos dos corpos de prova analisados, expresso em porcentagem. Os valores médios calculados para inchamento dos corpos de prova estão demonstrados na Tabela 1. 
TABELA 1: Resultados do ensaio de inchamento em espessura (mm).

\begin{tabular}{ccccc}
\hline Corpos de prova & $\begin{array}{c}\text { Espessura inicial } \\
(\mathrm{mm})\end{array}$ & após 2h & após 24h & Inchamento (\%) \\
\hline 1 & 17,60 & 18,00 & 18,00 & 2,27 \\
\hline 2 & 16,50 & 17,00 & 17,00 & 3,03 \\
\hline 3 & 17,00 & 17,50 & 17,50 & 2,94 \\
\hline 4 & 16,50 & 17,00 & 17,00 & 3,03 \\
\hline 5 & 16,00 & 16,00 & 16,00 & 3,13 \\
\hline 6 & 17,78 & 17,78 & 18,50 & 4,05 \\
\hline Média & & & & 3,07 \\
\hline Dsv. Padrão & & & 0,48 \\
\hline $\begin{array}{c}\text { Coef. de Variação } \\
(\%)\end{array}$ & & & 0,32 \\
\hline
\end{tabular}

Após 24h de imersão em água destilada, o inchamento médio dos corpos de prova foi de 3,07\%. O valor obtido para inchamento em espessura ficou abaixo do mínimo aceito pela norma NBR 14810 (2013), que estabelece o valor de 22\% para esta classe de material. Este fato se deve provavelmente, à boa adesão entre as partículas/fibras de bambu e a matriz polimérica (PVAc).

\subsubsection{Densidade}

A NBR 14810-2 (2013) indica o intervalo de 551 a $750 \mathrm{~kg} / \mathrm{m}^{3}$ para painéis de uso não estruturais em ambiente seco, porém o valor médio obtido foi inferior, portanto, não atendeu as indicações da norma brasileira.

A norma ANSI A208.1 (1999) indica o intervalo de valores de densidade para painel MDP entre 640 a $800 \mathrm{~kg} / \mathrm{m}^{3}$, deste modo o valor obtido não se enquadra nesta norma.

De acordo com a norma britânica WPIF 2G (2018), a densidade ideal fica na faixa entre 350 a $600 \mathrm{~kg} / \mathrm{m}^{3}$ para painéis de partículas de uso em ambientes internos secos, portanto o valor médio de $440 \mathrm{~kg} / \mathrm{m}^{3}$ obtido atende aos parâmetros indicados para esta norma.

De acordo com Weber (2011), quando os valores alcançados para densidade de um material compósito estão abaixo do que recomendam as normas possivelmente a prensagem por ser efetuada de maneira manual não obteve a compactação satisfatória e, portanto, não atingindo o valor da densidade esperada. 


\subsubsection{Ensaio de absorção de água}

Este ensaio teve como objetivo determinar qual 0 produto impermeabilizante/hidrofugante preserva por mais tempo a coesão dos elementos do compósito proposto. O pressuposto deste ensaio é a observação visual da desagregação dos elementos no decorrer do tempo e a absorção de água e, portanto, aumento da massa de cada corpo de prova. Dentre os impermeabilizantes utilizados a multi-seladora possivelmente é o tratamento mais eficiente como indicado pela norma ANSI 208, que indica que a absorção de água aceitável é de até 35\% (Tabela 2). Porém, de maneira geral, os tratamentos proporcionaram a redução na absorção de água quando comparados ao valor do corpo de prova sem tratamento, com exceção da linhaça, que apresentou valor de absorção maior.

TABELA 2: Resultado ensaio de absorção d'água.

\begin{tabular}{cccc}
\hline Tratamento & Massa inicial & Após 24h & Absorção \\
\hline Sem tratamento & 0,97 & 2,45 & $1,48(152 \%)$ \\
Multi-seladora & 1,55 & 2,08 & $0,53(34 \%)$ \\
Linhaça & 1,66 & 3,19 & $1,53(92 \%)$ \\
Goma laca & 1,57 & 2,29 & $0,72(46 \%)$ \\
Verniz acrílico & 1,55 & 2,37 & $0,82(53 \%)$ \\
Cera de carnaúba & 1,4 & 2,58 & $1,18(84 \%)$ \\
\hline
\end{tabular}

Após 48h da imersão dos corpos de prova os elementos começaram a ter uma desagregação. Primeiramente a desagregação ocorreu nos corpos de prova sem tratamento e nos tratamentos com linhaça e cera de carnaúba, em seguida o material tratado com goma laca e verniz acrílico, e por último a multi-seladora. Os valores dos resultados para absorção de água coincidiram assim com o estado de desagregação dos materiais. 


\subsection{PROPRIEDADES MECÂNICAS}

\subsubsection{Ensaio de compressão}

Os resultados obtidos nos ensaios foram demonstrados na Tabela 3. Os valores de MOE e MOR para compressão normal às fibras variaram de 2600 a $5172 \mathrm{MPa}$ e 4,14 a 5,42 MPa respectivamente e os valores de MOE e MOR para compressão paralela às fibras variaram de 1027,3 a 8025,0 e 4,75 a 6,60 respectivamente.

A Tabela 3 apresenta os resultados médios obtidos para os ensaios mecânicos de compressão normal e paralelo às fibras.

TABELA 3: Valores médios do módulo de ruptura (MOR) e módulo de elasticidade (MOE) para o ensaio de compressão dos corpos de prova da espécie Bambusa tuldoides

\begin{tabular}{ccc|ccc}
\multicolumn{2}{c|}{ Compressão Normal às fibras } & \multicolumn{3}{c}{ Compressão Paralela às fibras } \\
\hline Corpos de prova & MOE $(\mathrm{MPa})$ & $\begin{array}{c}\text { MOR } \\
(\mathrm{MPa})\end{array}$ & Corpos de prova & $\begin{array}{c}\text { MOE } \\
(\mathrm{MPa})\end{array}$ & $\begin{array}{c}\text { MOR } \\
(\mathrm{MPa})\end{array}$ \\
\hline 07 & 4667 & 4,14 & 13 & 1276,6 & 4,84 \\
08 & 5172 & 5,19 & 14 & 1162,0 & 4,75 \\
09 & 2842 & 4,63 & 15 & 1027,3 & 5,40 \\
10 & 4844 & 4,18 & 16 & 5113,0 & 6,60 \\
11 & 2600 & 4,71 & 17 & 8025,0 & 5,17 \\
12 & 3834 & 5,42 & 18 & 7690,0 & 5,66 \\
\hline Média & 3993 & 5,72 & Média & 9247 & 5,61 \\
\hline Dsv. Padrão & 10,82 & 0,51 & Dsv. Padrão & 28,31 & 0,69 \\
\hline Coef. de Variação & 27,10 & 11,01 & Coef. de Variação & 30,61 & 12,84 \\
$(\%)$ & & \multicolumn{4}{c}{ (\%) } \\
\hline
\end{tabular}

A norma indica os valores de MOR e MOE entre 14-16 MPa e 2300-3300 MPa, respectivamente. Observou-se, portanto, que os resultados dos ensaios obtiveram êxito apenas para o MOE (valores acima do estipulado por norma), ficando muito aquém dos valores da norma para o módulo de ruptura.

\subsubsection{Ensaio de flexão}

Os resultados obtidos para o Módulo de Ruptura e Módulo de Elasticidade em flexão estão apresentados na Tabela 4. Os resultados de MOR variaram de 5,13 a 6,35 e os resultados do MOE variaram de $1260 \mathrm{MPa}$ a $2180 \mathrm{MPa}$. 
TABELA 4: Valores médios do módulo de ruptura (MOR) e módulo de elasticidade (MOE) para o ensaio de flexão dos corpos de prova da espécie Bambusa tuldoides.

\begin{tabular}{ccc}
\hline Corpos de prova & MOE $(\mathrm{MPa})$ & MOR $(\mathrm{MPa})$ \\
\hline 19 & 1670 & 5,51 \\
20 & 1260 & 5,35 \\
21 & 1270 & 5,32 \\
22 & 2180 & 6,35 \\
23 & 1800 & 5,13 \\
24 & 2160 & 5,47 \\
\hline Média & 1723 & 5,35 \\
\hline Dsv. Padrão & 40,53 & 0,47 \\
\hline Coef. de Variação(\%) & 23,53 & 8,51 \\
\hline
\end{tabular}

A média do módulo de elasticidade da Bambusa tuldoides foi $1723 \mathrm{MPa}$, estando, portanto, dentro do indicado pela norma NBR 15316-2 (2019) e muito próximo ao valor da norma NBR 14.810-2 (2013). No entanto a média do módulo de ruptura de 5,35 MPa está bem abaixo dos valores indicados pelas duas normas que é de $11 \mathrm{MPa}$. Pela proximidade dos valores indicados pelas normas e dos resultados obtidos no ensaio, sinaliza razoável potencial do compósito para utilização em painéis não estruturais.

\subsection{CARACTERIZAÇÃO QUÍMICA}

\subsubsection{Espectroscopia por FTIR e Raman}

As medidas de FTIR foram realizadas em um espectrômetro Bruker (Vertex 70v). Os espectros das amostras foram adquiridos através do programa OriginPro Trial 2020 em varreduras no intervalo entre 4000 a $400 \mathrm{~cm}^{-1} \mathrm{e}$ interpretados de maneira computacional pela versão acadêmica do programa KnowltAll da empresa BioRad. A literatura revisada sugere que para cada banda de absorbância, há picos que podem estar associados a grupos funcionais característicos de materiais lignocelulósicos (SÁNCHEZ, 2017).

Os principais elementos químicos dos materiais lignocelulósicos são lignina, celulose, hemicelulose, amido, sílica e pectina. Os picos que podem sugerir a presença destes componentes foram mostrados na Figura 1 para o FTIR e Figura 2 para Raman. 
FIGURA 1: Espectroscopia FTIR da amostra in natura Bambusa tuldoides.

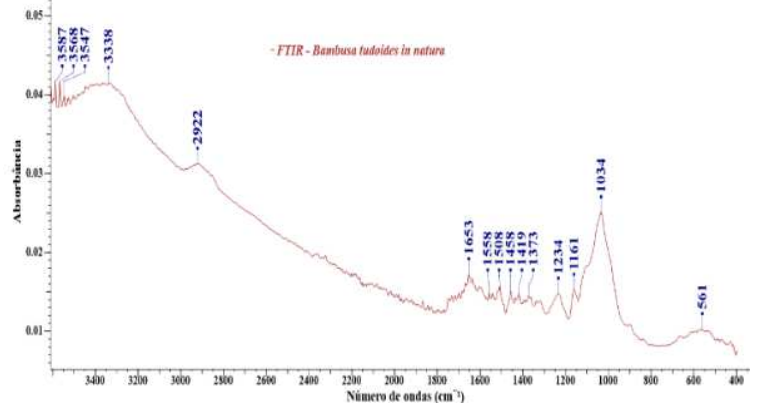

Fonte: autora, 2020.

FIGURA 2: Espectroscopia Raman da amostra in natura Bambusa tuldoides.

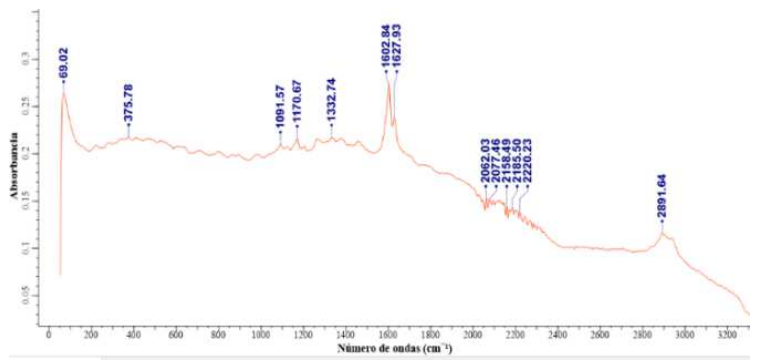

Fonte: autora, 2020.

Os resultados da análise FTIR e Raman em amostras de Bambusa tuldoides foram apresentadas e comparadas com a literatura. Segundo Liu (2013), as bandas entre $1600 \mathrm{a}$ $1450 \mathrm{~cm}^{-1}$ correspondem a região característica da lignina, hemicelulose, celulose e pectina. Os picos $1558,1508 \mathrm{~cm}^{-1}$ indicam a presença de lignina como também os picos 3338 e $1234 \mathrm{~cm}^{-1}$. Porém, o pico $1732 \mathrm{~cm}^{-1}$ indica a remoção parcial da lignina e hemicelulose.

Os picos 900 e $896 \mathrm{~cm}^{-1}$ podem ser atribuídos a ligações $\beta$-glicosídicas entre unidades de xilose na hemicelulose. As bandas entre 1458 e $1373 \mathrm{~cm}^{-1}$ podem indicar absorção típica da celulose. Os picos 1630 e $1639 \mathrm{~cm}^{-1}$ são atribuídos a vibração de alongamento presença de amido e $\mathrm{H}_{2} \mathrm{O}$ respectivamente.

De acordo com Liew (2015), a banda 3200 a $3500 \mathrm{~cm}^{-1}\left(3338 \mathrm{~cm}^{-1}\right)$ costuma indicar um aumento hidroxila e o pico $2921 \mathrm{~cm}^{-1}$ indica polissacarídeo $\mathrm{CH}$. O pico 561 indica a presença de $\mathrm{CBr}$. O pico $1735 \mathrm{~cm}^{-1}$ indica à ligação $\mathrm{C}=\mathrm{O}$ do grupo carboxílico de hemicelulose e pectina. $O$ espectro entre 60 e $90 \mathrm{~cm}^{-1}\left(69 \mathrm{~cm}^{-1}\right)$ indica a presença de sílica que se apresenta 
na espectroscopia Raman. O pico $600 \mathrm{~cm}^{-1}$ no FTIR indica a presença de C-Br (LEITE, 2012).

\subsubsection{Análise por $M E V$ da microestrutura das fibras e adesão das partículas/matriz}

A Microscopia Eletrônica de Varredura (MEV) consiste na análise da microestrutura de materiais in natura e compósitos. Objetivo é identificar por meio de imagens da microestrutura as modificações superficiais como defeitos, falhas, rupturas e interações das partículas/matriz. A Figura 3 (a) mostra a fibra de Bambusa tuldoides recoberta com PVAc (cola branca) e a presença de bolhas de ar marcadas pelas setas vermelhas. Na Figura 3 (b) as setas mostram as falhas no recobrimento de cola possivelmente resultado do rompimento das bolhas de ar.

FIGURA 3: MEV do compósito (a) e (b) fibras recobertas com PVAc

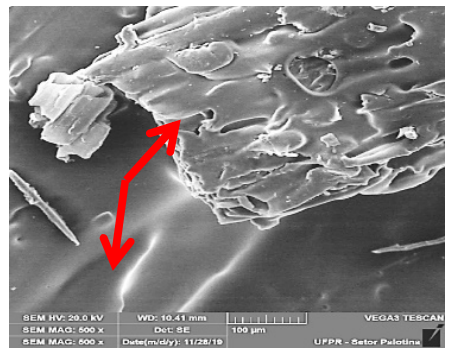

(a)

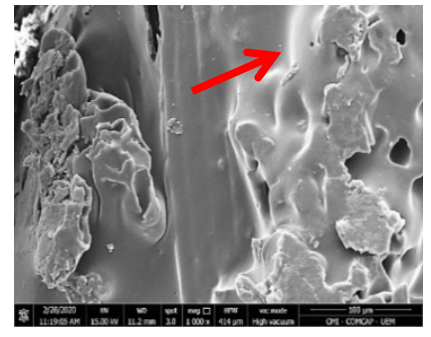

(b)

Fonte: Central de Microscopia-UEM, Central de Microscopia-UFPR.

A Figura 4(a) mostra as microfibrilas in natura com extremos rompidos (seta vermelha), mas interligadas parcialmente no sentido longitudinal, possivelmente pelas camadas residuais de lignina (seta azul). A Figura 4 (b) mostra que as fibras pós polpação não tiveram deslignificação total, pois várias fibras encontram-se parcialmente interligadas.

FIGURA 4: MEV da Bambusa tuldoides in natura: (a) (b) fratura das microfibrilas

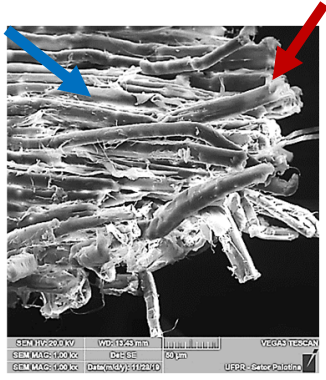

(a)

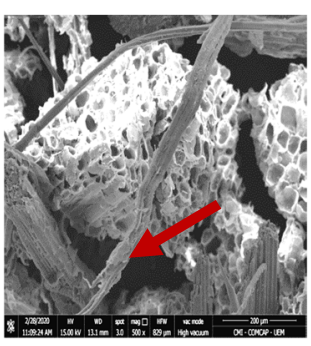

(b)

Fonte: Central de Microscopia-UEM, Central de Microscopia-UFPR (2019). 
Na Figura 5 (a) a seta indica a fratura da fibra da Bambusa tuldoides no compósito com falha de recobrimento do polímero. A Figura 5 (b) mostra uma malha de fibras com formação heterogênea com muitas falhas no recobrimento de PVAc. Essas lacunas podem indicar uma deficiência na homogeneização dos materiais na fase de compactação fato que possivelmente ocorreu por conta do ser efetuado manualmente.

FIGURA 5: MEV da Bambusa tuldoides com PVAc: (a) fibra fraturada com adesão parcial do PVAc; (b) malha de fibras recobertas parcialmente com PVAc.

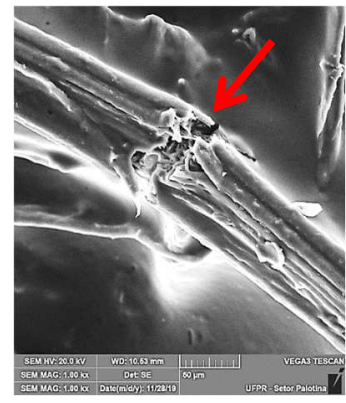

(a)

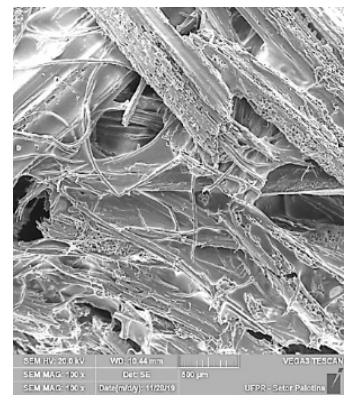

(b)

Fonte: Central de Microscopia-UFPR, Palotina (2019).

\subsubsection{Análise dos elementos inorgânicos por EDS}

As Figuras 6 (a) e (b) apresentam imagens do mapeamento elementar por EDS das amostras de Bambusa tuldoides in natura e com PVAc, respectivamente.

FIGURA 6: Elementos inorgânicos detectados em microanálise de EDS: Bambusa tuldoides in natura: (a); Bambusa tuldoides com PVAc (b).

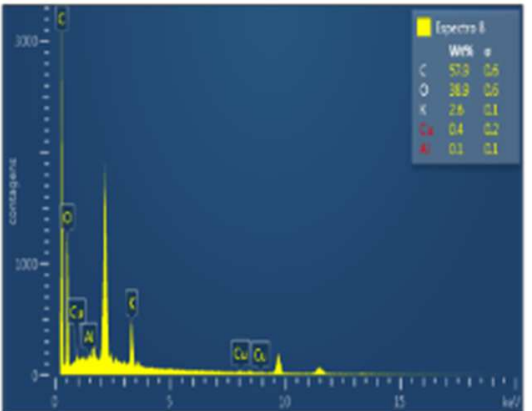

(a)

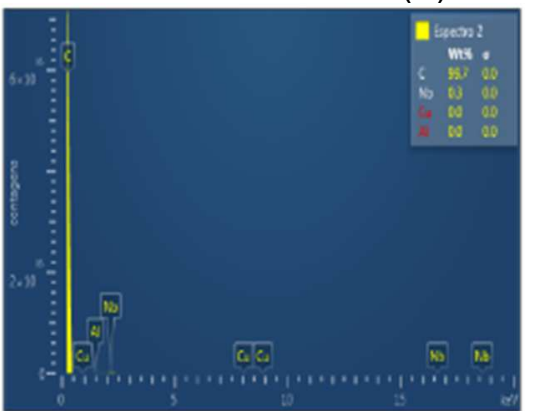

(b)

Fonte: Central de Microscopia-UEM, Maringá.

Nas duas imagens, os picos demonstrados identificaram elementos inorgânicos presentes nas amostras. Conforme as imagens foram constatadas a presença de pequenas 
concentrações de Cobre (Cu), Nióbio (Nb) e Alumínio (Al) em maior concentração Potássio $(\mathrm{K})$, Oxigênio $(\mathrm{O})$ e Carbono (C). A presença do metal Nióbio (Nb) na amostra de Bambusa tuldoides com PVAc possivelmente se relaciona a uma contaminação do ambiente interno do equipamento, pois sua ocorrência na natureza somente está associada a minerais.

\section{CONCLUSÃO}

O presente trabalho relacionou a utilização da fibra de bambu como material alternativo para arquitetura com 0 debate contemporâneo a respeito da sustentabilidade socioambiental local. Ante os resultados dos ensaios e análises efetuadas foi possível deduzir algumas considerações que seguem relatadas. No processo de confecção dos corpos de prova verificou-se que somente é possível o uso do material fibroso completamente seco, pois quando úmido tende a se formar uma massa comprometendo a seleção granulométrica em peneiras. Dentre as diversas metodologias para produção de painéis descrita na literatura, o processo escolhido foi o de polpação/deslignificação das fibras com água em meio mecânico por se mostrar o mais sustentável. $O$ ensaio de compressão não possui normas para a modalidade de compósitos, então como referência foram utilizados os valores da norma europeia. Os resultados do MOE e MOR atenderam aos valores indicados na EN 310 (1999).

Os valores para os ensaios de flexão atenderam a indicações da norma NBR 14810-2 (2018). O ensaio atingiu a ruptura para todos os corpos de prova, possibilitando assim determinar o módulo de ruptura (MOR). A densidade média para os compósitos confeccionados apenas atendeu as recomendações das normas britânicas, indicando que podem haver ocorrido falhas no adensamento do material. Em relação aos valores médios obtidos pelo ensaio de inchamento em espessura em $2 \mathrm{~h}$ e $24 \mathrm{~h}$ os resultados para as duas espécies atenderam as especificações da norma NBR 14810-2 (2018).

As análises FTIR e Raman, complementares, demonstraram a presença de celulose, hemicelulose, lignina, pectina, amido e sílica. Estes elementos químicos estão indicados na bibliografia de referência. As microanálises realizadas por meio de MEV mostram as microestruturas e suas rupturas das fibras e a presença de grânulos de amido e lignina residuais. As células do parênquima, os orifícios e as rugosidades descobertos por meio da polpação mecânica também são apresentadas nas imagens das fibras in natura. Nas 
imagens dos compósitos foram mostradas as poucas falhas na cobertura das fibras pelo adesivo e a presença de algumas bolhas de ar. A análise por EDS mostrou a presença de alguns elementos químicos inorgânicos que constituintes do material lignocelulósico in natura: Alumínio (Al), Cloro (Cl), Carbono (C), Oxigênio $(\mathrm{O})$ e Potássio $(\mathrm{K})$.

\section{REFERÊNCIAS}

ABRAF. Anuário estatístico ABRAF 2013 ano base 2012 / ABRAF. - Brasília: 2013. AMERICAN NATIONAL STANDARDS INSTITUTE. ANSI-A-208.1-87: mat-formed wood particleboard. New York, 1987. 9 p.

ASSOCIAÇÃO BRASILEIRA DE NORMAS TÉCNICAS. ABNT. NBR 7190: Projeto de estruturas de madeira. Anexo B: determinação das propriedades das madeiras para projetos de estruturas. Rio de Janeiro. 107 p., 1997.

ASSOCIAÇÃO BRASILEIRA DE NORMAS TÉCNICAS. ABNT. NBR 14810: chapas de madeira aglomerada: parte 2: requisitos. Rio de Janeiro, 2002. 4 p.

ASSOCIAÇÃO BRASILEIRA DE NORMAS TÉCNICAS. ABNT. NBR 15316-2: Painéis de fibras de média densidade. Parte 2: requisitos e métodos de ensaio. Rio de Janeiro, 2019. $4 \mathrm{p}$.

AZZINI, A.; GONDIM-TOMAZ, R. M. A.; ERISMANN, N. DE M. Desfibramento de Cavacos Laminados de Bambusa vulgaris Schrad visando a extração de amido. Bragantia, Campinas, v. 57, n. 1, p., 1998.

BARBOSA, F. R. et al. Espectroscopia Raman e infravermelho em fibras óticas e em sílica, 1979.

BERALDO, A. L. Bambu: características e aplicações na construção civil e em arquitetura / Antonio L. Beraldo e Luiz Roberto P. Aleixo. - 1.ed. - Bauru, SP: Canal6, 2019. 108 p.; $21 \mathrm{~cm}$.

BERALDO, A. L.; AZZINI, A.; CARVALHO, J. F. Barreira acústica de bambu: uma avaliação preliminar. III ENECS-Encontro nacional sobre edificações e comunidades sustentáveis, 2003.

D'AMELIA, R. P. et al. Quantitative analysis of copolymers and blends of polyvinyl acetate (PVAc) using Fourier transform infrared spectroscopy (FTIR) and elemental analysis (EA). World J. Chem. Educ, v. 4, n. 2, p. 25-31, 2016.

EUROPEAN COMMITTEE FOR STANDARZATION. European Standard EN 310 - Woodbased panels - Determination of modulus of elasticity in bending and of bending strength. Bruxelas, 1993.

FREDERICCI, C. et al. Aplicação da espectroscopia Raman na identificação de minerais asbestiformes. Revista IPT: Tecnologia e Inovação, v. 1, n. 1, 2016.

GUERREIRO, C. I., LIZARAZU, M. A., 2010. Flowering of Bambusa tuldoides (Poaceae, Bambusoideae, Bambuseae) in southern South America. Darwiniana, 48(1), 25-31. 
HUANG, P., CHANG, W., ANSELL, M., CHEW, J., SHEA, A. (2015). Density distribution profile for internodes and nodes of Phyllostachys edulis (Moso bamboo) by computer tomography scanning. Construction and Building Materials, v. 93, p.197-204, 2015.

INDÚSTRIA BRASILEIRA DE ÁRVORES - IBÁ. Relatório Annual 2019.

JAYARAMAN, D., LONG, T.T. Manual for Sustainable Management of Clumping Bamboo. INBAR Technical Report 41. Beijing, China: INBAR, 2019. Disponible en: https://resource.inbar.int/upload/file/1578457574.pdf

LEITE, D. de O.; PRADO, R. J. Espectroscopia no infravermelho: uma apresentação para o Ensino Médio. Rev. Bras. Ensino Fís., São Paulo, v. 34, n. 2, p. 1-9, June 2012.

LIEW, F. K. et al. Synthesis and characterization of cellulose from green bamboo by chemical treatment with mechanical process. Journal of Chemistry, 2015.

LIU, Z.; FEI, B. Characteristics of moso bamboo with chemical pretreatment. Sustainable Degradation of Lignocellulosic Biomass: Techniques, Applications and

Commercialization, p. 3-14, 2013.

MALONEY, T. M. The family of wood composite materials. Forest Products Journal, v.46, n.2, p.19-26, Feb. 1996.

MERA, T.; XU, C. Plantation management and resource economics of bamboo in China. Ciencia y Tecnología. v 7, n.1, 2014.

MORAIS, W. W. C. et al. Uso de Bambusa tuldoides e Eucalyptus grandis para confecção de painéis aglomerados. Ciência Florestal, Santa Maria, v. 28, n. 2, p. 746-757, 2018.

OSTAPIV, F. Produção e uso de materiais compósitos bambu-PET na construção civil popular. Capítulo de: Bambus no Brasil, da Biologia à Tecnologia. 1a ed. ICH-Instituto Ciência Hoje, pág, v. 494, 2017.

PEREIRA, M. A. R.; BERALDO, A. L. Bambu de corpo e alma. Bauru, SP: Canal 6, 2016.

RODRIGUES, A. De G.; GALZERANI, J. C. Espectroscopias de infravermelho, Raman e de fotoluminescência: potencialidades e complementaridades. Revista Brasileira de Ensino de Física, v. 34, n. 4, p. 1-9, 2012.

SÁNCHÉZ, M. L. et al. Physical and mechanical properties of agglomerated panels made from bamboo fiber and vegetable resin. Construction and Building Materials. p. 156, 330-339, 2017.

VIEIRA, A. J. T. et al. Aplicação da fibra de bambu aos sistemas industrializados para desenvolvimento de placas de concreto. Veredas Favip-Revista Eletrônica de Ciências, v. 9, n.1, p. 92-106, 2016.

WEBER, C. Estudo sobre viabilidade de uso de resíduos de compensados, MDF e MDP para produção de painéis aglomerados. Dissertação (mestrado) - Universidade Federal do Paraná, Setor de Ciências Agrárias, Programa de Pós-Graduação em Engenharia Florestal. Curitiba. 2011.

WPIF - WOOD PANEL INDUSTRIES FEDERATION -. Panel Guide, annex 2G. 2018. Disponível em:< http://www.wpif.org.uk.>. Acesso em: 01 de maio de 2020. 